\title{
Introducción a la epigenética en las patologías
}

\author{
[Introduction to epigenetics in pathologies]
}

Karen Geneve Castillo-Hernández¹, Marta Elena Hernández-Caballero², María José López-Ibarra ${ }^{3,4}$, José Darío Martínez-Ezquerro ${ }^{4}$

1 Escuela de Ciencias de la Salud, Universidad Marista de Mérida

${ }^{2}$ Facultad de Medicina, Benemérita Universidad Autónoma de Puebla (BUAP)

${ }^{3}$ Doctorado en Biomedicina y Biotecnología Molecular, Escuela Nacional de Ciencias Biológicas (ENCB), Instituto Politécnico Nacional (IPN)

${ }^{4}$ Unidad de Investigación Médica en Genética Humana, Centro Médico Nacional Siglo XXI, Instituto Mexicano del Seguro Social (IMSS)

\section{Introducción}

El concepto de epigenética emerge del concepto "epigénesis" propuesto en la década de 1940 por Waddington. Epigénesis es definida como una deducción lógica de que durante el desarrollo del organismo; deben de existir mecanismos que residen sobre (epi), el nivel genético y pueden controlar su expresión ante estímulos específicos. De tal manera podemos entender y definir la epigenética como la rama de la biología que estudia la modulación de la expresión del genotipo hacia un fenotipo particular o como el estudio de los cambios en la función genética que son heredables, pero no modifican la secuencia de nucleótidos en el DNA. Por otro lado, el epigenoma se refiere al conjunto de cambios epigenéticos a lo largo de todo el genoma. Los múltiples mecanismos epigenéticos finalmente llevan a la cromatina hacia una forma abierta o cerrada, permitiendo el silenciamiento o expresión de los genes. 
Mientras que los cambios genéticos impactan directamente en la secuencia de nucleótidos del DNA de manera irreversible, los cambios epigenéticos producen cambios en grupos celulares, que bajo ciertas condiciones pueden ser reversibles, tales cambios influyen directamente en la estructura de la cromatina y los cromosomas, estas modificaciones epigenéticas son dinámicas que pueden ser potenciadas o removidas bajo ciertos estímulos. Pueden ser provocadas por una variedad de factores, que incluyen la influencia del medio ambiente durante el desarrollo fetal e infancia, compuestos químicos, edad, hábitos alimenticios, ejercicio, estrés, exposición a drogas, procesos inflamatorios y envejecimiento, así como el uso prolongado de algunos medicamentos.

La relación entre los genes y los factores epigenéticos es dinámica e inter-regulada, es decir, los cambios epigenéticos pueden influir en la expresión genética y a su vez, algunas mutaciones genéticas pueden causar disfunciones epigenéticas. La modulación inadecuada en esta relación también puede ser la causa del desarrollo o progresión de múltiples enfermedades.

La cromatina se encuentra organizada en dos tipos estructurales: la heterocromatina y eucromatina. La heterocromatina corresponde a la mayor parte del material nuclear, que incluye a los telómeros y regiones pericentroméricas de los cromosomas. El resto del genoma está conformado por eucromatina, la cual es transcripcionalmente activa y rica en genes. Los grados de compactación de la cromatina y movilidad de los nucleosomas son dos parámetros estructurales importantes: la transcripción activa se encuentra asociada con una baja condensación de la cromatina y con nucleosomas dinámicos y en contraparte la inactividad de la transcripción se encuentra asociada con una cromatina rígida, esto debido a la alta compactación y a la presencia de los nucleosomas estáticos. Para que se pueda acceder a la estructura de la molécula de DNA, muchas proteínas conocidas como "remodeladores" o "modificadores" o inclusive componentes estructurales no histónicos como factores de transcripción (FTs) y RNAs polimerasas alteran la estructura de la cromatina, lo que origina los cambios en el posicionamiento de los nucleosomas y los contactos de DNA-Histonas. De esta manera se prepara el DNA para la replicación, la reparación, la recombinación, la transcripción; sin embargo, algo 
importante que ocurre de igual forma en las diferentes modificaciones presentes en el DNA, es que dirigen los cambios durante la condensación de la cromatina, la cual regula el ingreso de la maquinaria transcripcional y por lo tanto la expresión génica.

Los elementos y/o complejos que se encuentran participando en la regulación epigenética, son responsables del control de la expresión génica en conjunto con la estructura de la cromatina, estos participan principalmente en generar el acceso sobre el DNA para llevar a cabo procesos biológicos esenciales para la célula regulando la accesibilidad a la cromatina mediante la hidrólisis de ATP para modular la estructura de la cromatina y movilizar a los nucleosomas mediante un proceso giratorio tanto del propio nucleosoma como del DNA, lo que conlleva a las interacciones de tipo DNA-histona entre estos podemos encontrar a la metilación del DNA, las modificaciones post-traduccionales de las histonas, los complejos del remodelamiento de la cromatina ATP-dependientes, los complejos SWI/SNF, entre otros.

\section{Metilación del DNA}

La metilación del DNA implica la adición covalente de un grupo metilo en el carbono 5 de los residuos de citosina $(5 \mathrm{mC})$ y se detecta comúnmente en citosinas seguidas por guaninas, es decir, en secuencias del dinucleótido $\mathrm{CpG}$ (islas $\mathrm{CpG}$ ). Las regiones metiladas frecuentemente corresponden a regiones promotoras, pero pueden presentarse también en regiones de grandes secuencias repetidas como los centrómeros o los retrotransposones (elementos de DNA que primero se transcriben a una plantilla de RNA y luego son transcritos de modo reverso a DNA, para posteriormente insertarse en una región del genoma). Las regiones promotoras tienden a estar protegidas de la metilación, sin embargo, la presencia de un promotor metilado o no metilado difiere de célula a célula, permitiendo así, su diferenciación a un tipo celular propio de cada tejido durante el desarrollo.

Pero ¿cómo es que la metilación del DNA se asocia con el silenciamiento de un gen? En primer lugar, la metilación de CpGs en el DNA conduce a la condensación de la cromatina porque hay proteínas que reconocen a las CpGs metiladas, específicamente MeCP1 y 
MeCP2 tienen papeles relevantes durante el desarrollo embrionario, contribuyendo al inicio o mantenimiento de estado represivo. Estas proteínas tienen dominios de unión preferencial a nucleosomas para represión transcripcional, remodelación y desacetilación.

Existen tres tipos de enzimas que agregan grupos metilo conocidas como DNA metiltrasferasas (DNMTs): la DNMT1, quien se asocia con PCNA (antígeno nuclear de células en proliferación por sus siglas en inglés; es el factor que se encarga de afianzar la DNA polimerasa al DNA durante la replicación) y a los focos de replicación, tiene preferencia por DNA hemimetilado. Por lo tanto, se encarga de mantener los patrones de metilación existentes una vez que ha ocurrido la replicación del DNA. La DNMT1 es reclutada al DNA recientemente replicado hemimetilado gracias a su proteína asistente UHRF1, restaurando la simetría de la metilación al agregar grupos metilo a las cadenas de DNA recién sintetizadas. Por otro lado, las DNMT3A y DNMT3B junto con DNMT3L (esta última difiere de las primeras dos porque carece de dominio de metiltransferasa), se encargan de la metilación de novo de islas CpG de DNA de doble cadena. Por lo que estas enzimas son las responsables del establecimiento del patrón de metilación durante el desarrollo embrionario temprano.

Una modificación adicional a la 5 -metilcitosina $(5 \mathrm{mC})$ es su oxidación a 5hidroximetilcitosina por una familia de proteínas dioxigenasas de metilcitosina dependientes de 2-oxoglutarato, $\mathrm{Fe}+$, conocidas como proteínas TET, lo que lleva a la eliminación del grupo metilo represor por un mecanismo que involucra al proceso de reparación por escisión de bases. Como desmetilasas de DNA que son, las proteínas TET modulan la transcripción genética al regular de forma dinámica la metilación del DNA, por un lado, la regulan al unirse a regiones ricas en $\mathrm{CpG}$ evitando la actividad de las DNA metiltransferasas y por otro, controlan la metilación al convertir la $5 \mathrm{mC}$ en $5 \mathrm{hmC}$ (Figura 1). 

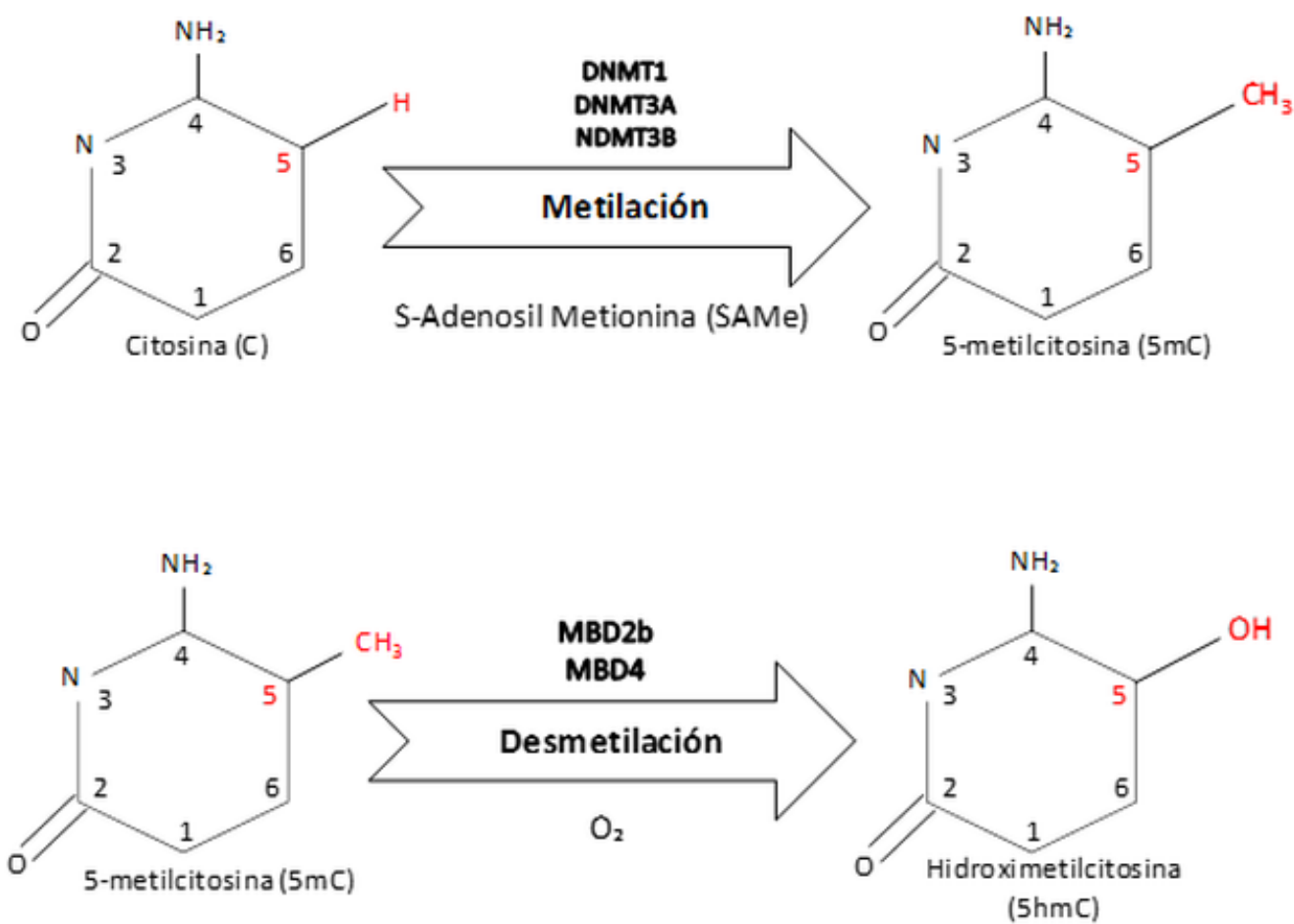

Figura 1. Las DNA metiltrasferasas (DNMTs) DNMT1, DNMT3A, DNMT3B son las encargadas de agregar grupos metilo al DNA transfiriéndolo de la S-adenosil metionina hacia los residuos de citosina, lo que lleva a la formación de 5 -metilcitosina y S-adenosil-homocisteina. Mientras que en la desmetilación participan enzimas como la MBD2b y MBD4 que convierten la $5 \mathrm{mC}$ a 5 hidroximetilcitosia (Modificado de Alokail y Alenad, 2015).

\section{Modificaciones de las histonas}

Un paso determinante en el control del uso de la información genética dentro de la célula comienza con el empaquetamiento del DNA alrededor de las histonas durante la formación de la cromatina. La conformación que adquiere la cromatina regula el cómo se expresen los genes y su actividad depende de modificaciones postraduccionales en las proteínas histonas. Las histonas pueden ser modificadas por diversos procesos, entre los cuales está la metilación en residuos de lisina ( $\mathrm{K}$, en el código de una sola letra) y arginina $(R)$. Una lisina en una histona que puede ser mono, bi o tri-metilada mientras que la arginina puede ser sólo mono o di-metilada, esta metilación de histonas se asocia con activación o silenciamiento de genes. 
Los patrones de modificación de las histonas son regulados por proteínas que "escriben", es decir, agregan que, "leen" o interpretan, que "borran", o remueven esas modificaciones químicas. Es la combinación de esas modificaciones en regiones específicas del DNA, la que actúa como un código de histonas que produce cambios en la estructura de la cromatina abriéndola o cerrándola, haciéndola más o menos accesible a la transcripción. Aquí un ejemplo de esas combinaciones: es bien sabido que la trimetilación de la lisina 4, 36 o 79 en la histona H3 (H3K4me3, H3K36me3 and H3K79me3), la monometilación de H4K20 y H2BK5 (H4K20me y H2BK5me) y la acetilación de H3K9 y H3K14 tiene como resultado la activación de genes, mientras que la di o trimetilación de H3K9 (H3K9me2 y H3K9me3) y la trimetilación de H3K27 provocan la represión de genes (Figura 2). Otros cambios que favorecen la activación de genes son la fosforilación de H3 y la ubiquitinación de H2B.
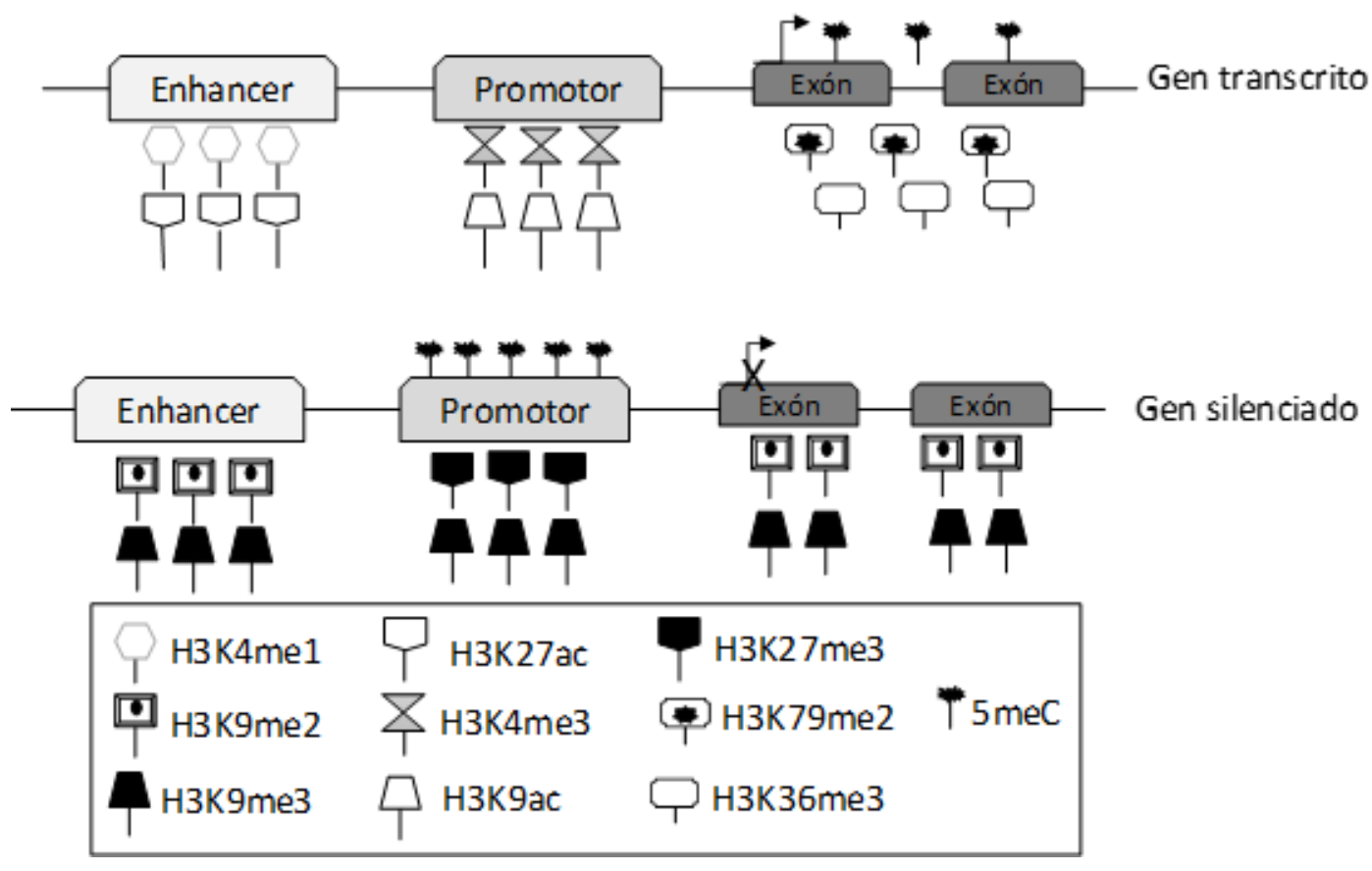

Figura 2. Diversas marcas epigenéticas sirven para mantener a un gen active o para reprimirlo. De esta manera potenciadores (enhancers) activos, promotores y el cuerpo de un gen se encuentran marcados por H3K4me1+H3K27ac, H3K4me3+H3K9ac, y H3K79me2+H3K36me3, respectivamente. Mientras que genes con $5 \mathrm{meC}$ en su promotor son inactivos y tienen además H3K27me3, potenciadores inactivos y el cuerpo del gen marcados con H3K9me2/3 (Modificado de Yan et al. 2016). 
La metilación de la lisina la llevan a cabo enzimas llamadas histona lisina metiltransferasas y desmetilasas, ambos tipos de enzimas se asocian y son reguladas por dominios de unión a cromatina que reconocen marcas de metilación distintivas.

Entre las proteínas escritoras de modificaciones están las lisinas metiltransferasas (KMTs), las histonas acetiltrasferasas (HATs) y las cinasas. Mientras que entre las proteínas borradoras se encuentran las lisinas desmetilasas (KDMs), las histonas desacetilasas (HDACs) y las fosfatasas. Otro grupo de proteínas son las lectoras de la información epigenética, las proteínas lectoras son estructuralmente diversas, aunque poseen uno o más dominios modulares efectores que reconocen "leen" modificaciones covalentes tanto en proteínas como en el DNA. Los cromodominios son la clase fundadora de las proteínas lectoras del código de histonas metil-lisina, otros lectores incluyen a los módulos efectores homeodominio de planta (PHD), dominio tudor, bromodominio y extra-terminal (BET), todos ellos forman parte integral del mecanismo de control de la transcripción.

Las histonas desmetilasas (HDMs) son enzimas que remueven las marcas de metilo sobre las histonas y su función es antagónica a la de las histonas metiltransferasas (HMTs). La primera HDM identificada fue la peptidilarginina deaminasa 4 (PADI4), esta enzima dependiente de $\mathrm{Ca} 2+$ convierte los residuos de arginina en citrulina. Al hacer esto, la PAD4 evita la metilación de la arginina en las colas $\mathrm{N}$-terminal de las histonas a través de las HMTs, mientras que la desmetilación de la lisina la llevan a cabo la desmetilasa 1 específica de lisina (LSD1) y las desmetilasas que contienen el dominio Jumonji C (JmjC). LSD1 desmetila su sustrato a través de una reacción de oxidación amina dependiente de FAD, desmetila a H3K4me1, H3K4me2, H3K9me1 y H3K9me2. La segunda clase de desmetilasas que contienen el dominio catalítico JMJC, desmetilan los residuos de histona a través de una reacción de dioxigenasa dependiente de Fe (III) y a-cetoglutarato como cofactores. JHDM3A por ejemplo, desmetila la histona trimetilada H3K9 y al residuo H3K27.

La complejidad en la modificación de las histonas se hace aún mayor debido a que los residuos de lisina de las histonas son capaces de albergar al menos 8 modificaciones 
covalentes diferentes que incluyen además de la acetilación y la mono, bi y tri-metilación, a la ubiquitinación y sumoilación.

\section{Remodelación de la cromatina}

La gran cantidad de DNA que alberga el genoma humano está empacada en alrededor de 30 millones de nucleosomas que se organizan en dominios funcionales de cromatina. Cambios en el espaciamiento de los nucleosomas tienen como resultado una modificación en la cromatina, favoreciendo o dificultando el acceso de los factores de transcripción al DNA. Las proteínas remodeladoras de la cromatina son críticas para crear sitios de acceso a la secuencia de DNA.

Señales extracelulares y citoplásmicas como la presencia de factores de crecimiento, citosinas, hormonas o metabolitos, le permiten a la maquinaria de transcripción eucarionte reclutar a los remodeladores de cromatina hacia el gen blanco, permitiendo su expresión a través de la regulación de la accesibilidad a la secuencia de DNA.

Hay dos tipos de complejos que actúan de forma cooperativa para regular la estructura de la cromatina. Una clase de esos complejos modifica las colas de las histonas de forma covalente mientras que el otro tipo de complejo requiere de la hidrólisis de ATP para cambiar la posición y espaciamiento del nucleosoma, facilitar el intercambio de nucleosomas o la incorporación de variantes de histonas como la H2B. Los complejos de remodelación de cromatina permiten la compactación y descompactación del DNA sin afectar su capacidad para la replicación, expresión selectiva de genes, reparación y recombinación. Por lo tanto, los remodeladores actúan como integradores de señales hacia el núcleo; a la fecha se conoce la existencia de al menos 4 familias de complejos remodeladores de cromatina bien caracterizados: el complejo SWI/SNF, la familia ISWI, la familia CHD y la familia de inositol 80 , INO80.

Hasta ahora, todos los modelos propuestos para el deslizamiento de los nucleosomas por remodeladores de cromatina asumen que sólo una pequeña fracción de las 358 interacciones directas e indirectas DNA-histona se interrumpen en un momento dado de la reacción, ya que la hidrolisis del ATP no provee energía suficiente para desorganizar 
la estructura de la nucleoproteína. Los nucleosomas pueden ser "buenos" sustratos, es decir, tener sitios de unión de alta afinidad o pueden ser "malos" sustratos por tener sitios de unión de baja afinidad para las enzimas de remodelación. Las células expresan una gran variedad de complejos de remodelación que actúan simultáneamente sobre la cromatina. Los complejos remodeladores se difunden libremente a través del núcleo buscando "buenos" nucleosomas, pero el nucleosoma que puede ser un buen sustrato para un complejo remodelador puede ser uno malo para un complejo diferente, lo que se correlaciona con la activación o represión de determinados genes. De ahí que se ha sugerido que la mezcla y la concentración individual de los complejos remodeladores en la célula determinan la arquitectura global de la cromatina que puede responder a una señal específica y no responder a otra. De forma general, por la acción de los diversos complejos de remodelación se sugiere que la cromatina es similar a un código de barras con los nucleosomas ubicados en posiciones sitio-específicas y que esas combinaciones definen potencialmente la identidad de un tipo celular.

Debido a que los complejos remodeladores contienen dominios lectores pueden reconocer modificaciones covalentes sobre la cola de las histonas, por ejemplo, las lisinas acetiladas sobre una cola son reconocidas por medio de los bromodominios, de esa forma la unión del bromodominio de Tip5, la subunidad grande de NoRC a la H4K16ac es un prerrequisito para el funcionamiento de NoRC (complejo remodelador de cromatina que contiene SNF2h). Alteraciones en esta unión como la presencia de una mutación puntual dentro del bromodominio, altera la asociación de NoRC con la cromatina, evitando que se forme la heterocromatina y eliminando la represión transcripcional, mientras que las lisinas metiladas sobre las histonas son reconocidas por los cromodominios y los homeodominios de planta (PHD); por ejemplo, la proteína Chd1 inter- actúa con $\mathrm{H} 3 \mathrm{~K} 4 \mathrm{me} 2 / 3$ a través de su cromodominio doble. 


\section{Complejo SWI/SNF}

El complejo SWI/SNF (por sus siglas en inglés, SWltch/Sucrose Non Fermentable) fue identificado en un inicio en levaduras y se ha encontrado que los genes involucrados con este complejo presentan cierto grado de homología entre diferentes especies. Este complejo en mamíferos (mSWI/SNF) contiene al menos 14 subunidades las cuales son codificadas por 28 genes y esto hace que se generen una extensa diversidad de complejos para funciones especializadas en diferentes tejidos específicos y a su vez, esta diversidad es dada por aquellas subunidades con actividad ATPasa que son mutuamente exclusivas dentro de los complejos; por ejemplo, SMARCA2 (Brahma o BRM) o SMARCA4 (BRM/gen 1 relacionado a SWI2 o BRG1) y por otra parte, el núcleo de subunidades que se encuentra ampliamente expresado como es: SMARCB1 (SNF5, INI-1 o BAF47), SMARCC1 (BAF155) y SMARCC2 (BAF170). Sin embargo, estudios recientes han identificado nuevas subunidades dentro del complejo mSWI/SNF y estos hasta el momento no se han identificado homólogos dentro del complejo SWI/SNF en levaduras. La función principal de SWI/SNF es que sus subunidades interactúen con FTs localizados en los promotores y potenciadores que modulan la expresión génica y contribuyen a una especificación sobre los linajes celulares, la diferenciación y el desarrollo. Existen estudios que han encontrado a las subunidades catalíticas SMARCA4 (BRG1) o SMARCA2 (BRM) frecuentemente inactivas en líneas celulares establecidas. Hay que resaltar que la función bioquímica precisa de este complejo no es tan clara, sin embargo, estudios in vitro han demostrado que SWI/SNF es capaz de movilizar y "expulsar" al octámero de histonas en el DNA. Posiblemente, las evidencias más claras provienen de los estudios sobre la diferenciación neural, en donde se puede observar que el complejo SWI/SNF genera una progresión y diferenciación de progenitores neurales a neuronas post-mitóticas. También se ha observado que, en células troncales embriogénicas, este complejo contiene un ensamblado distintivo de acuerdo con las subunidades presentes en SWI/SNF el cual colabora sobre el mantenimiento en el estado de las células troncales embriogénicas y la pluripotencialidad. Otro ejemplo, es dado por el factor de determinación muscular, MYOD que puede ser directamente incorporado dentro del complejo SWI/SNF, lo que resulta en la transcripción de los genes blancos de MYOD. Similarmente, OLIG2 (por sus siglas en inglés, Oligodendrocyte- 
Specific BHLH Transcription Factor 2) también ha sido asociado físicamente con este complejo, específicamente en los potenciadores de oligodendrocitos específicos, durante la diferenciación. De esta forma, el complejo SWI/SNF puede contribuir a la interacción especificas con FTs y por la vía de subunidades que son blancos para uniones con el DNA y dominios de unión de histonas, que incluyen a los grupos de motilidad ARID, HSA, PHD y a los bromodominios, los cuales se encuentra en el núcleo de este complejo.

\section{Ácidos nucleicos circulantes y epigenética}

Diversos escenarios clínicos incluyendo el cáncer, enfermedades autoinmunes, como la artritis reumatoide y el lupus eritematoso sistémico; infecciones bacterianas, fúngicas, protozoarias y virales, como la tuberculosis, aspergilosis, tripanosomiasis y la hepatitis, respectivamente; el embolismo pulmonar, así como condiciones tan distintas como el infarto, el embarazo y los trasplantes, aparentemente no comparten ninguna característica. Sin embargo, una manifestación común que comparten quienes presentan estas condiciones junto con las personas sin enfermedad aparente, es la presencia de ácidos nucleicos circulantes (ANcir), tanto de ácido desoxirribonucleico (DNA) como ribonucleico (RNA) fuera de sus células, circulando libremente en su sangre.

La presencia de ácidos nucleicos (DNA y RNA) circulantes se ha demostrado tanto en plantas como en animales. En las plantas, los ácidos nucleicos extracelulares se movilizan en el xilema y floema, así como en los plasmodesmos. En animales, siendo los humanos de nuestro principal interés en este libro, los ANcir pueden detectarse en distintos fluidos corporales como sangre (suero y plasma), saliva, orina, leche materna, fluido amniótico, pleural, sinovial, broncoalveolar, cerebroespinal, entre otros.

La presencia extracelular de ácidos nucleicos ocurre en todas las personas independientemente de su condición clínica, desde personas sanas y mujeres embarazadas, hasta que han recibido trasplantes de órganos o presentan alguna enfermedad.

Por ello, distintos grupos de investigación a nivel mundial tienen puesta su mira en el desarrollo de la tecnología de los ANcir como método de detección, diagnóstico, 
pronóstico y monitoreo de una gran diversidad de condiciones de importancia clínica, principalmente a partir de plasma y suero sanguíneos.

El genoma circulante se refiere al conjunto de secuencias de DNA extracelular que pueden detectarse en distintos fluidos corporales. Dichos fragmentos varían entre $500 \mathrm{y}$ 21 mil pares de bases, provenientes principalmente de las células normales o tumorales con núcleo, sus mitocondrias, de bacterias y virus, así como de la ingesta alimentaria.

Por otro lado, el transcriptoma circulante hace referencia al conjunto de transcritos extracelulares, tanto codificantes (RNAm) como no codificantes (ncRNA, por sus siglas en inglés), que circula libremente en los fluidos corporales de las personas sanas o que padecen alguna patología. Dichos transcritos circulantes varían entre 18-28 y 70 nucleótidos principalmente, y provienen de fuentes endógenas además de fuentes exógenas, incluyendo bacterias, hongos, insectos y alimentos.

En el siguiente capítulo se revisará el origen de los ácidos nucleicos circulantes (ANcir), los mecanismos que permiten su estabilidad y, por lo tanto, su detección en los fluidos corporales, así como las alteraciones genéticas y epigenéticas que pueden presentar los ANcir en diversas condiciones clínicas. Estas características evidencian el potencial de los ANcir en la detección, diagnóstico y monitoreo de diversas condiciones clínicas, a partir del análisis genético o epigenético de las llamadas «biopsias líquidas», las cuales permiten el muestreo poco invasivo y recurrente del estado sistémico-molecular de los pacientes.

Finalmente, el tema de los ácidos nucleicos circulantes se aborda de una manera novedosa y desde la perspectiva de las ciencias de la complejidad, integrando la funcionalidad de estas moléculas informativas que circulan en los distintos fluidos corporales, independientemente de su origen endógeno o exógeno, pero con la capacidad de regular la expresión génica de las células receptoras y modificar el estado de salud-enfermedad de los organismos: el exoepigenoma. 


\section{Referencias}

1. Alokail M, Alenad M. DNA Methylation in: A Concise Review of Molecular Pathology of Breast Cancer. Edited by Mehmet Gunduz. 2015, 55 p., ISBN 978- 953-51-2030-8

2. Arita K, Shimizu T, Hashimoto H, Hidaka Y, Yamada M, Sato M. Structural basis for histone N-terminal recognition by human peptidylarginine deiminase 4. Proc Natl Acad Sci, USA. Apr 2006, 4; 103 (14): 5291-6.

3. Blus BJ, Wiggins K, Khorasanizadeh S. Epigenetic virtues of chromodomains. Crit Rev Biochem Mol Biol. 2011 Dec; 46 (6): 507-26.

4. Dimitrova E, Turberfield AH, Klose RJ. Histone demethylases in chromatin biology and beyond. EMBO Rep. 2015 Dec; 16 (12): 1620-39.

5. Kadoch C, Crabtree GR. Mammalian SWI/SNF chromatin remodeling complexes and cancer: Mechanistic insights gained from human genomics. Sci Adv. 2015 Jun 12; 1 (5): e1500447.

6. Kurdistani SK. Histone modifications in cancer biology and prognosis. Prog Drug Res. 2011; 67: 91-106.

7. Li B, Carey M, Workman JL. The role of chromatin during transcription. Cell. 2007 Feb, 3; 128 (4): 707-19.

8. Martínez-Ezquerro JD. Consecuencias de la transferencia horizontal de genes en la evolución genómica eucarionte. UNAM. Facultad de Ciencias; 2010.

9. Narlikar GJ, Sundaramoorthy R, Owen-Hughes T. Mechanisms and functions of ATP-dependent chromatin-remodeling enzymes. Cell. 2013 Aug 1; 154 (3): 490-503.

10. Portela A, Esteller M. Epigenetic modifications and human disease. Nat Biotechnol. 2010; 28 (10): 1057-1068

11. Tahiliani M, Koh KP, Shen Y, Pastor WA, Bandukwala H, Brudno Y, et al. Conversion of 5-methylcytosine to 5-hydroxymethylcytosine in mammalian DNA by MLL partner TET1. Science 2009, 324 (5929): 930-935 
12. Torres IO, Fujimori DG. Functional coupling between writers, erasers and readers of histone and DNA methylation. Curr Opin Struct Biol. 2015 Oct 19; 35: 68-75.

13. Wang Y, Wysocka J, Sayegh J, Lee YH, Perlin JR, Leonelli L, et al. Human PAD4 regulates histone arginine methylation levels via demethylimination. Science. 2004 Oct 8; 306 (5694): 279-83

14. Weber CM, Henikoff S. Histone variants: dynamic punctuation in transcription. Genes Dev. 2014 Apr 1; 28 (7): 672-82.

15. Yan H, Tian S, Slager SL, Sun Z, Ordog T. Genome-Wide Epigenetic Studies in Human Disease: A Primer on-Omic Technologies. Am J Epidemiol. 2016 Jan 15; 183 (2): 96-109. 